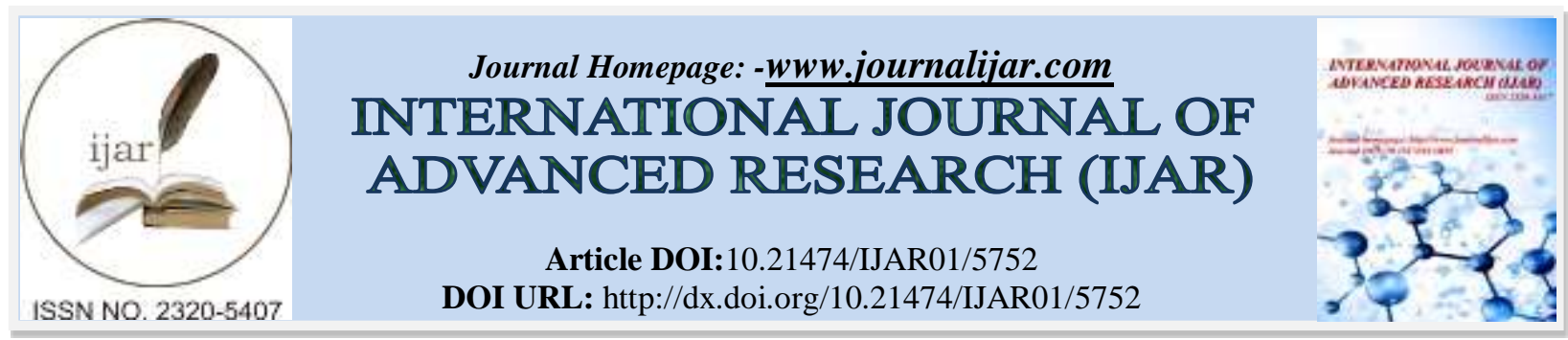

RESEARCH ARTICLE

\title{
CHALLENGES AND POSSIBILITIES IN HYDROPONICS: AN INDIAN PERSPECTIVE.
}

\author{
Shailesh Solanki ${ }^{1}$, Nitish Gaurav ${ }^{1}$, Geetha Bhawani ${ }^{2}$ and ${ }^{*}$ Abhinav Kumar ${ }^{3}$. \\ 1. Department of Agriculture, Noida International University, Greater Noida. \\ 2. Department of Chemistry, Noida International University, Greater Noida. \\ 3. IILM College of Engineering and Technology, Department of Biotechnology, KP-II, GreaterNoida.
}

\section{Manuscript Info}

Manuscript History

Received: 03 September 2017

Final Accepted: 05 October 2017

Published: November 2017

Key words:-

hydroponics, nutriculture, soilless culture.

\begin{abstract}
Hydroponics (Greek words 'hydro' water and 'ponos' labour) is a technique of plant growing without soil using with mineral nutrient solutions. It is also called "Controlled environmental Agriculture" (CEA). Hydroponics, a water culture, now used in both research and commercial field. Some countries successfully implemented this technique for fast growing horticulture crops such as strawberries, lettuce, tomatoes and carnation. In this technique water culture scientists discovered that as compared to soil based growth ,hydrophonic plant system needs only small number of inorganic elements in addition to water, oxygen, and sun light to grow the plant Hydroponics farming can be a major advantage for Indian agriculture; it has the potential to produce crops in every season without soil. Such practices can help Indian farmers to increase their crop productivity even in small fragmented lands. This review paper focus on the challenges and possibilities to bring soil less farming in India to ensure its stability so that it may prove more beneficial for Indian farmers to grow crops which are $100 \%$ organic, toxic free and of better quality.
\end{abstract}

Copy Right, IJAR, 2017,. All rights reserved.

\section{Introduction:-}

Soil contains all the important components for the growth of plants. It provides nutrients; water etc. for successful growth of plants. All the important beneficial process such as nitrogen fixation, providing moisture and whole plants generation happen due to presence of soil.

Plants, however needs a large space and open field to grow whereas in the urban areas space is one of the limiting factors for any type of agriculture production. To overcome this limitation, hydroponics was developed by plant scientists recently. The term hydroponics was derived from Greek word 'hydro' means water and 'ponos' means labor ${ }^{[8] .}$ This system is most effective to help face challenges of climate changes and also helps in production of crops and vegetable which is $100 \%$ safer to eat. For hydroponics technology, no soil is required to grow some selected demanded crops. It is also termed as (soil less culture) technique where crops are grown in liquid based nutrient rich solutions under green house.

As it is well known hydroponics does not require any soil, where root system is supported using inert medium such as clay pellets, pertile, gravels etc. ${ }^{[2]}$. The purpose behind this is to allow the plants roots to come in direct contact with nutrients solutions, while having access to oxygen, which is essential for proper growth ${ }^{[9]}$ 
The global demand for foods grains and other vegetables are increasing every year. Our country India is no exception to this. This technique can be an alternative to Indian agriculture system, which still depends upon age old techniques.

Indian farmer are not much aware of hydroponics systems, as it require some skills to operate this system. The main challenge is low literacy rate among farmers, which is low and in order to prepare them, we need to guide maximum number of farmers so that those farmers could guide and teach another one.

For the farmers those have less fragmented land can perform hydroponic culture in greenhouse to increase crop productivity. In cases of crop loss by natural disaster, they must have another option of farming to survive and grow organic, pesticides free vegetables which would further enhance economic growth of our country.

\section{Advantage of Hydroponics:-}

(1) Hydroponic methods produce healthy crops with high yield, no chance of soil borne insects and pests; diseases attack or weed infestation too.

(2) Soil less culture provides organic food and there is no use of pesticides and harmful toxics too.

(3) It need less space in consumption to soil garden, as plant with small root can be grown closer to each other.

(4) Crops grow two times faster in hydroponics and yield is doubled leading to more production from same amount of space.

(5) No wastage of water as water is reversed used in this technique uses only $1 / 20^{\text {th }}$ of water to crops compare to traditional farming.

(6) Requires less labour.

(7) No worries of changing seasons, crops can be grown all year around.

(8) Hydroponics is abiotic stress less free farming technique.

(9) Environment friendly practice, no harm to nature.

Possibilities:-

(1) Providing more number of training to farmers.

(2) Providing them hydroponics system at affordable rates.

(3) For hydroponics urban areas should be projected to build hydroponic food park in every city.

(4) Agricultural universities and Research institution should work in co-operation with Government of India to perform survey and try to bring this techniques at large scale so that farmers could learn something from it.

(5) Farming should give most respected profession in Nation so that young farmers could see his/her future in fields in agriculture working with latest agricultural techniques.

\section{Limitations:-}

Along with several benefits, hydroponics also has some limitations. A large scale application set up requires technical knowledge. Further set up cost is also high, which also require constant supervision. During hydroponics techniques water based diseases can easily be introduced due to poor handling. Another major limitation is that not all crops can be grown by these methods. Some examples are carrot and potatoes. Other limitations are temperature, humidity and $\mathrm{pH}$.

\section{Challenges:-}

Hydroponics system cost is high, so it is not affordable by poor farmers of India. It requires deep skills and practical knowledge to grow crops. Less awareness, so result is unfocused sector of agricultural in India. Providing skills and training to all types of farmers from poor to average is not an easy task. Ensure for better outcome and high yields commitment for the farmer and helping them to create interest is another reason. If the farmers willin to work in this area, and having less knowledge about system, they need to hire a horticulturist or skilled staff. And to hire a staff at affordable salary is actually a big problem.

\section{Scope for Hydroponics in India: -}

Hydroponics has been used successfully in some countries like Israel which has a dry and arid climate. Hydroponics is the fastest growing sector of agriculture, could be very useful for food production in the future. As the population is increasing day by day and land decline due to poor management, people shifts their focus on new technology like Hydroponics and Aeroponics to feed nation. Due to changes in climatic factors and natural disaster like drought and floods, are some of the reasons to switch to new technology, which promises food productions safely. 


\section{Different techniques for soil less culture:-}

Large no of techniques in available for soil less culture but following factors are considered in the selection of technique.

(1) Available space.

(2) Suitable media for growth.

(3) Expected productivity

(4) Expected quality etc.

Techniques of hydroponics:-

The wick system: It is seen as most simple hydroponic system. The Wick system is described as a passive system, it means there are no moving parts. From the bottom reservoir, your specific Growth Technology nutrient solution is drawn up through a number of wicks into the growing medium. This system can use a variety of mediums, perlite, soil or coco.

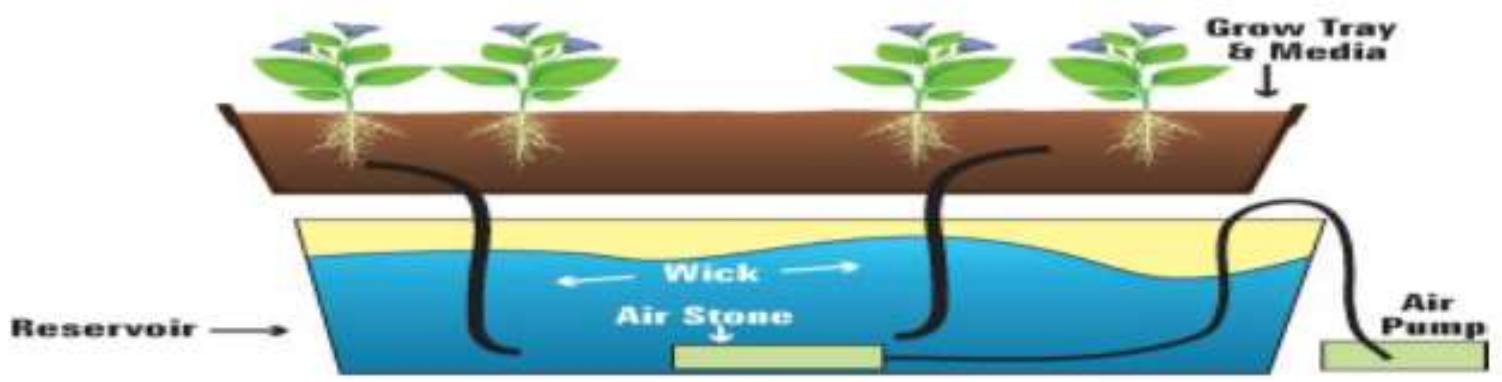

Water Culture:-

Fig.1:- Illustration of the wick system.

This system is an active system with moving parts. The roots of the plant are totally immersed into the water which contains the specific Growth nutrient. An air pump with helps oxygenate the water and allow the roots to breathe. Few plants other than lettuce can do well in this type of system.

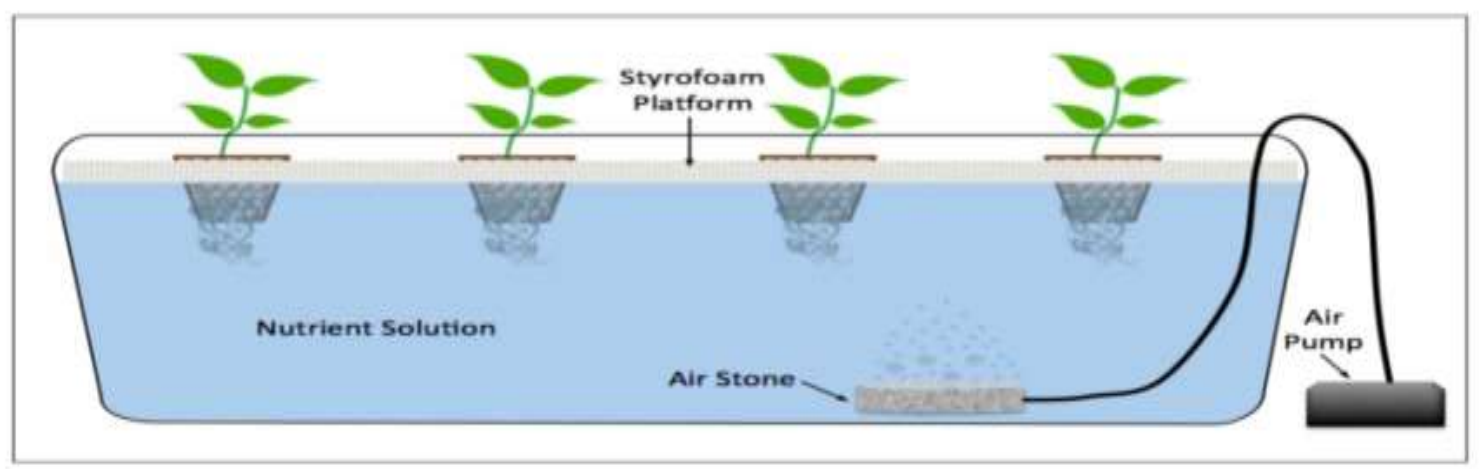

Figure 2:-Illustration of the water culture system. In this system the platform that holds the plants is usually made of Styrofoam and floats directly on the nutrient solution.

\section{Ebb \& Flow System (Flood \& Drain):-}

This hydroponic system works by temporarily flooding the grow tray. The nutrient solution from a reservoir surrounds the roots before draining back. This action is usually automated with a water pump on a timer. 


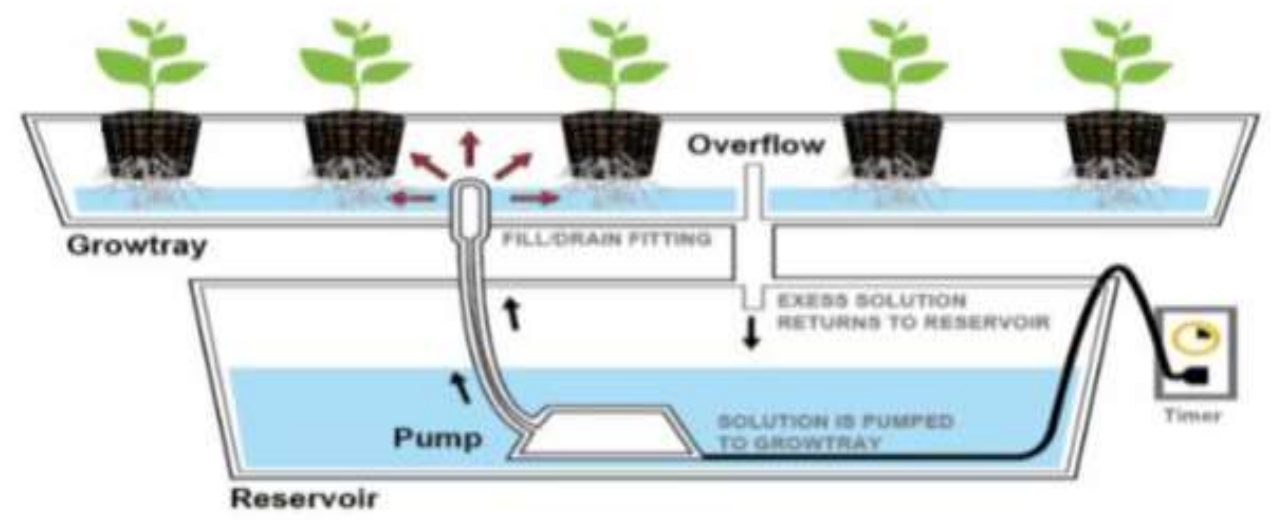

Fig.3:- Illustration of the EBB and Flow system

\section{NFT System:-}

The Nutrient Film Technique (N.F.T) system is at the forefront of people's minds when hydroponics is mentioned. The N.F.T uses a constant flow of the Growth Technology nutrient solution (therefore no timer is required). The solution is pumped from a reservoir into the growing tray. The growing tray requires no growing medium. The roots draw the nutrients from the flowing solution. The downward flow pours back into the reservoir to be recycled again. Pump and electric maintenance is essential to avoid system failures, where roots can dry out rapidly when the flow stops.

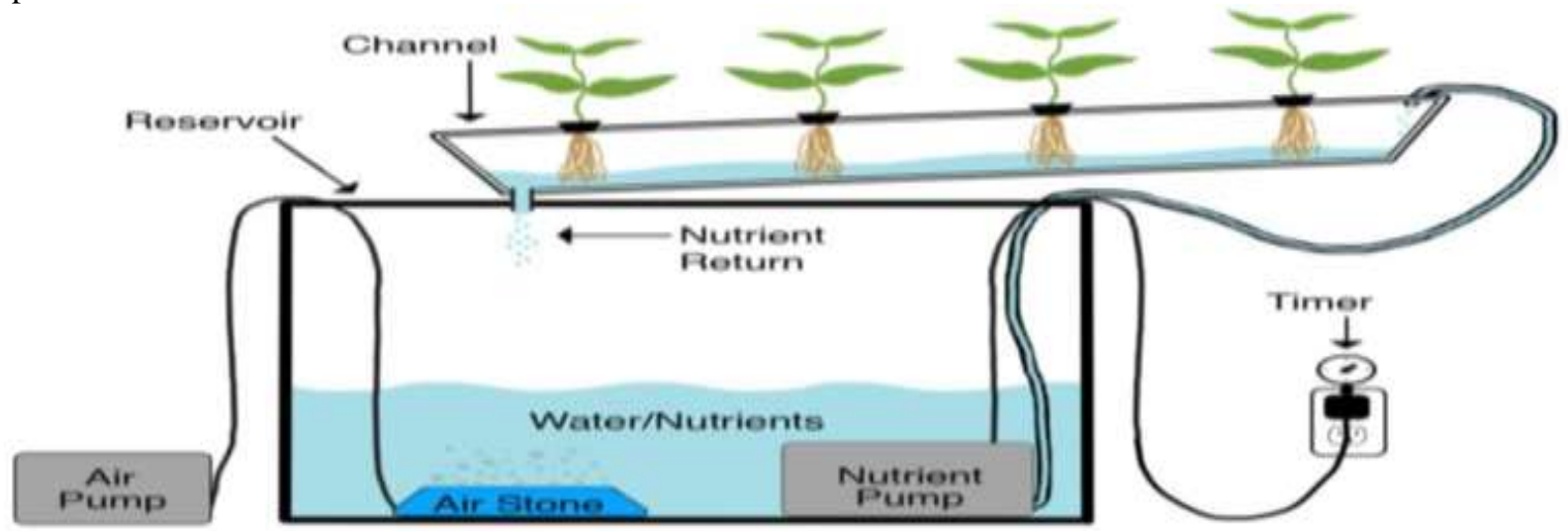

Figure 4:- Illustration of the Nutrient Film Technique system.

\section{Aeroponic System:-}

Aeroponic systems are high end technology method of hydroponic growing. Like the N.F.T system the growing medium is primarily air. In this method, the roots are hanged in air and are misted with nutrient solution. The misting of roots is usually done every few minutes. The roots will dry out rapidly if the misting cycles are interrupted. A timer controls the nutrient pump much like other types of hydroponic systems, except the aeroponic system needs a short cycle timer that runs the pump for a few seconds every couple of minutes. 


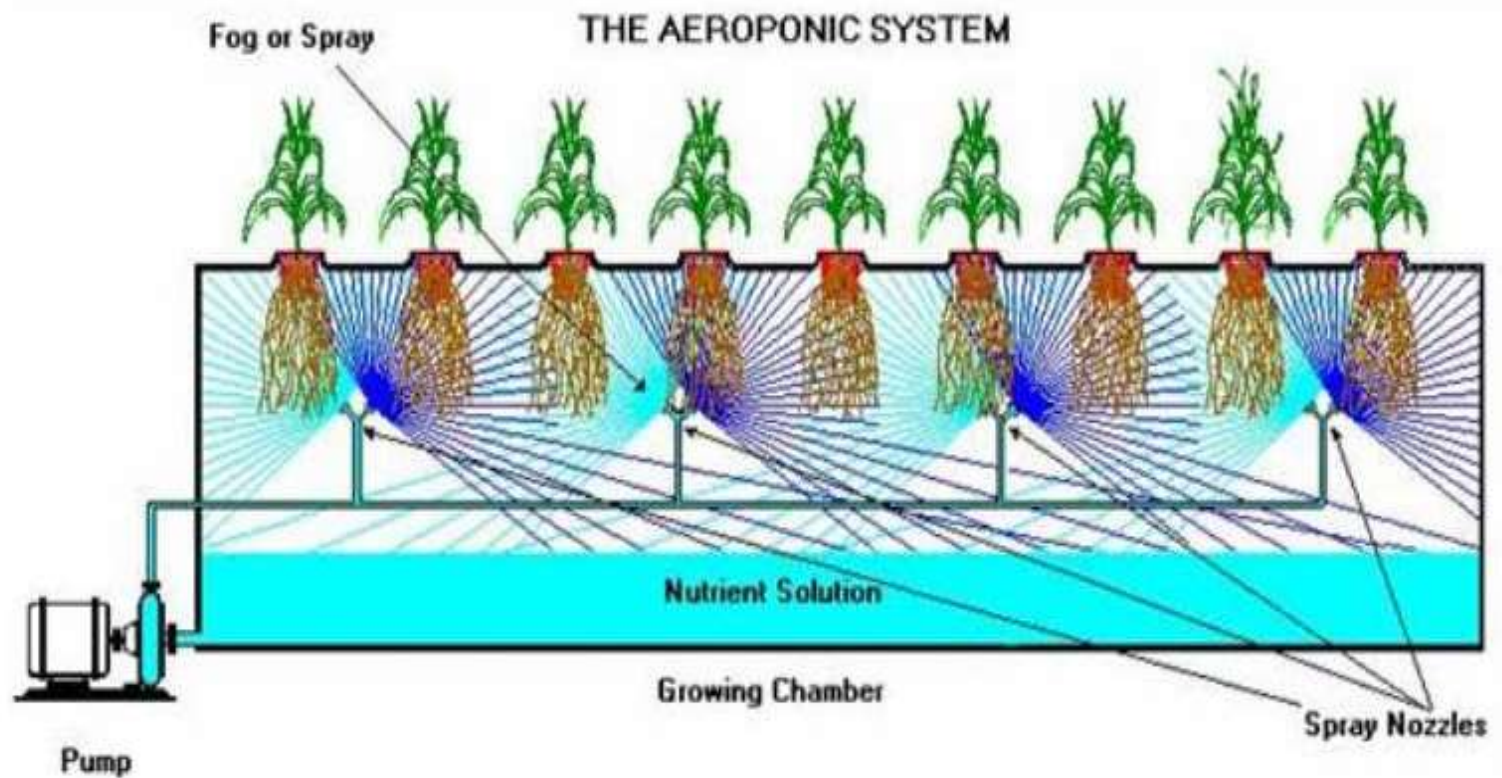

Fig.5:- Illustration of the aeroponic system.

Table No. 1:-Source of nutrients

\begin{tabular}{|l|l|l|} 
Source Elements & Characters \\
\hline KNO3 & , K & VERY SOLUBLE SALT \\
\hline POT.PHOSP.MONOBASIC (KH2PO4) & P,K & CORRECT PHOSPHOROUS DEFINE \\
\hline MGSO4 & S,MG & CHEAP,HIGHER SOULUBLE,PURE SALT \\
\hline IRON CHELATE & FE,CIT & BEST SOURCE OF IRON \\
\hline BORIC ACID & B & BEST SOURCE OF BORON \\
\hline CALCIUM NITRATE & N,CA & VERY SOULUBLE SALT \\
\hline
\end{tabular}

Table No. 2:-Hydroponic kit cost (approximate cost in India)

\begin{tabular}{|l|l|}
\hline NS20 (plant/frame $=10)$ area $=4.5$ sq. feet & RS 6000 (1 PIECE) \\
\hline NS40 & RS 12000 \\
\hline NS 60 & RS 18000 \\
\hline NS 80 & RS 23000 \\
\hline
\end{tabular}

A frame NFT - 32,000 Plant/ frame- 100 plants

Table No. 3:- List of crops Type Of Crops

Name Of Crops

\begin{tabular}{|l|l|}
\hline VEGETABLES & $\begin{array}{l}\text { TOMATO, CHILLI, BEET, CAULIFLOWER, MELONS, CUCUMBER, } \\
\text { CABBAGE }\end{array}$ \\
\hline FRUIT & STRAWBERRY \\
\hline CONDIMENTS & MINT, PARSLEY \\
\hline FLOWER & MARIGOLD \\
\hline MEDICINAL & ALOE VERA \\
\hline FODDER & BARLEY, SORGHUM \\
\hline LEAFY & LETTUCE \\
\hline
\end{tabular}

Table No. 4:- Comparison B/W Soil Less Vs Soil Crops Productivity/Arce

\begin{tabular}{|l|l|l|}
\hline & HYDROPONIC/ARCE & TRADITIONAL/ARCE \\
\hline TOMATO & 180 TONS & $5-10$ TONS \\
\hline CAULIFLOWERS & $30,000 \mathrm{LB}$ & $10-1500 \mathrm{LB}$ \\
\hline LETTUCE & $21,000 \mathrm{LB}$ & $9,000 \mathrm{LB}$ \\
\hline
\end{tabular}




\begin{tabular}{|l|l|l|}
\hline CUCUMBER & $28,000 \mathrm{LB}$ & $7,000 \mathrm{LB}$ \\
\hline CABBAGE & $10-12$ TONS & $6-7$ TONS \\
\hline LADY FINGER & $19,000 \mathrm{LB}$ & $5-8000 \mathrm{LB}$ \\
\hline PEAS & $14,000 \mathrm{LB}$ & $2,000 \mathrm{LB}$ \\
\hline
\end{tabular}

\section{Conclusion:-}

Hydroponic systems are highly effective techniques used in several agricultural domains and also against natural calamities. However this system requires less number of workers, but still it is expensive and complex but the productivity is high. This idea can be switched to more economical method or development of some equipment can be done by the farmer or concerned person All the hydroponics system requires the $\mathrm{P}^{\mathrm{H}}$ and nutrient levels check so, knowledge of these are a must. Any nation can increase their food productivity by focusing on such system, either set up urban farms or food parks under government supervision or either in villages. This system if used in a wise manner, can lead to the self sustenability.

\section{Acknowledgement(s):-}

Author AK is funded by SERB, Govt.of India. All the images are taken from google images.

\section{References:-}

1. Britto, D.T. \&Kronzucker, H.J. (2002): NH4+ toxicity in higher plants: a critical review. Journal of Plant Physiology 159 (6): 567-584.

2. Cramer, G.R. (2002) Sodium-calcium interactions under salinity stress. In: Salinity: Environment-PlantsMolecules, A. Lauchli\& U. Luttge:205-227, Kluwer Academic Publishers, Dordrecht, Netherlands

3. Dreccer, M.F., Ogbonnaya, F.C. \&Borgognone, M.G. (2004): Sodium exclusion in primary synthetic wheats. Proceedings of 54th Australian Cereal Chemistry Conference and 11th Wheat Breeding Assembly, C.K. Black, J.F. Panozzo\& G.J. Rebetzke: 118-121, Royal Australian Chemical Institute, Melbourne, Australia

4. Drihem, K. \&Pilbeam, D.J. (2002): Effects of salinity on accumulation of mineral nutrients in wheat growth with nitrate-nitrogen or mixed ammonium: nitrate-nitrogen. Journal of Plant Nutrition., 25 (10): 2091-2113

5. Wangwilbulkit, M., Vajrodaya S.,(2016): Ex-situ propagation of Pogostemonhelferi (Hook. f.) Press using tissue culture and a hydroponics system. Agriculture and natural resources 50: (20-25).

6. Farnoosh ,A., Asghar, G., Golabi, H.M., (2016): Interaction effects of water salinity and hydroponic growth medium on eggplant yield, water-use efficiency, and evapotranspiration. Journal Internetional soil and water conservation research., 99-106

7. Saha, S., Monroe, A., Day, M.R., (2016): yield, plant quality and nutrition of basil (Ocimumbasilicum L.) under soilless agricultural systems. Journal- annals of agriculture science, 61: 181-186.

8. Sardare M.D., Shraddha V., Admane2 A review on plant without soil - Hydrophonics. Journal International Journal of Research in Engineering and Technology (02): 03 Mar-2013.299-304.

9. Anuragputra, P., Yuliando, H., ( 2015): Soil less culture system to support water use efficiency and product quality: A review Agriculture and Agriculture science Procedia, 3: (283-288)

10. Sonneveld, C., (2000): Effects of salinity on substrate grown vegetables and ornamentals in greenhouse horticulture .PhD Thesis, University of Wageningen, The Netherlands

11. Savvas, D., (2002): Nutrient solution recycling in hydroponics. In: Hydroponic Production of Vegetables and Ornamentals (Savvas D; Passam H C, 299-343. Embryo Publications, Athens, Greece

12. Samreen, T.H., Shah, H.U., Ullah,S., Javid, M.,(2013): Zinc effect on growth rate, chlorophyll, protein and mineral contents of hydroponically grown mungbeans plant (Vignaradiata). Arabian journal of Chemistry

13. Van Os E A; GielingT. H., Ruijs M. N. A., (2002): Equipment for hydroponicinstallations. In: HydroponicProduction of Vegetables and Ornamentals (Savvas D; Passam H C, 103-141. Embryo Publications, Athens, Greece

14. Shavrukov, Y., Genc, Y., Hayes, J., (2012): The use of hydrophonics in abiotic stress tolerance research. Journal-A standard methodology for plant biological research. 3(39-66). 